\title{
Converting Metals into Phosphides: A General Strategy for the Synthesis of Metal Phosphide Nanocrystals
}

\author{
Amanda E. Henkes, Yolanda Vasquez, and Raymond E. Schaak* \\ Department of Chemistry, Texas A\&M University, College Station, TX 77842-3012
}

Chemicals. All metal salts were purchased from Alfa Aesar and used as received.

Trioctylphosphine (90\%), trioctylphosphine oxide, triphenylphosphine (99\%), tetra-noctylammonium bromide (98\%), sodium borohydride (98\%), oleic acid, hexadecylamine (90\%) and toluene were from Alfa Aesar. Octyl ether (99\%), oleylamine (70\%), hexanes and 1,2hexadecanediol (90\%) were from Sigma Aldrich. All reactions were carried out under argon using standard air-free techniques.

Characterization. Powder x-ray diffraction was performed on a Bruker-AXS GADDS diffractometer using microdiffraction techniques. Electron microscopy and electron diffraction were performed on a JEOL 2010 transmission electron microscope.

\section{Synthesis of metal nanoparticle precursors.}

Palladium. Pd nanoparticles were synthesized using a modification of Hyeon's procedures. ${ }^{1}$ $23.2 \mathrm{mg} \mathrm{Pd}(\mathrm{acac})_{2}$ were heated in $2.0 \mathrm{~mL}$ TOP at $220^{\circ} \mathrm{C}$ for $30 \mathrm{~min}$, precipitated with ethanol, isolated by centrifugation, washed with ethanol, and dried under argon.

Gold. Au nanoparticles were prepared according to Grebinski's methods. ${ }^{2} 13.1 \mathrm{mg}$ $\mathrm{HAuCl}_{4} \cdot 3 \mathrm{H}_{2} \mathrm{O}$ were dissolved in $0.625 \mathrm{~mL}$ nanopure water. Separately, $21.0 \mathrm{mg}$ tetra-noctylammonium bromide was stirred in $0.825 \mathrm{~mL}$ toluene under argon. The aqueous $\mathrm{Au}^{3+}$ solution was added to the toluene solution. Then, $0.01 \mathrm{~mL}$ TOP dissolved in $0.200 \mathrm{~mL}$ toluene was added dropwise until the solution changed from clear dark red to milky white. $6.1 \mathrm{mg}$ $\mathrm{NaBH}_{4}$ in $0.500 \mathrm{~mL}$ nanopure water was added dropwise. The reaction was stirred 30 minutes, then the toluene layer extracted and saturated with ethanol. The particles were isolated via centrifugation, washed with ethanol, and dried under argon.

Rhodium. Rh nanoparticles were prepared by sonicating a solution of $28.4 \mathrm{mg} \mathrm{RhCl}_{3} \cdot \mathrm{xH}_{2} \mathrm{O}$ in $1.000 \mathrm{~mL}$ oleylamine and injecting the solution into $2.0 \mathrm{~g}$ hexadecylamine at $260^{\circ} \mathrm{C}$. The solution was then heated 1 hour at $260^{\circ} \mathrm{C}$, followed by cooling and addition of 3:1 ethanol:hexanes to precipitate particles. The particles were isolated by centrifugation, washed with 3:1 ethanol:hexanes, and dried under argon. 
Platinum. Pt nanoparticles were prepared by sonicating $47.8 \mathrm{mg} \mathrm{Pt(acac)} 2$, $42.9 \mathrm{mg}$ 1,2hexadecanediol, $100 \mu \mathrm{L}$ oleylamine and $100 \mu \mathrm{L}$ oleic acid in $2.00 \mathrm{~mL}$ octyl ether. The solution was then heated under argon at $230^{\circ} \mathrm{C}$ for 1 hour. The solution was cooled and ethanol added to precipitate particles. The particles were isolated via centrifugation, washed with ethanol and dried under argon.

Nickel. Two methods were used to prepare Ni nanoparticles of varying size and dispersity. The first method is identical to the above method for preparing Pt nanoparticles, except $85.3 \mathrm{mg}$ $\mathrm{Ni}$ (acac) $2,166.5 \mathrm{mg}$ 1,2-hexadecanediol, $200 \mu \mathrm{L}$ oleylamine, $200 \mu \mathrm{L}$ oleic acid and $4.00 \mathrm{~mL}$ octyl ether were used. The second method is a modification of Hyeon's method ${ }^{3}$ in which 210.0 $\mathrm{mg} \mathrm{Ni(acac)} 2$ and $2.80 \mathrm{~mL}$ oleylamine were heated to $100^{\circ} \mathrm{C}$ and injected into $2.5 \mathrm{~g}$ triphenylphosphine at $215^{\circ} \mathrm{C}$. The solution was heated at $200{ }^{\circ} \mathrm{C}$ for 30 minutes, then cooled. The particles were precipitated with ethanol, isolated via centrifugation, washed with ethanol and dried under argon.

Conversion of metal nanoparticles into metal phosphides. Conversion reactions were carried out by dispersing pre-made metal nanoparticles in TOP and injecting the solution into hot TOP, TOPO, or octyl ether as described below.

Table 1: Synthetic variables for the conversion of metal nanoparticles into phosphides

\begin{tabular}{|l|l|l|l|}
\hline Product & Metal Nanoparticles/TOP & Solvent & Conditions \\
\hline $\mathrm{Ni}_{2} \mathrm{P}$ & $22.2 \mathrm{mg} \mathrm{Ni}+1.0 \mathrm{~mL}$ TOP & $2.00 \mathrm{~mL}$ octyl ether & $\begin{array}{l}\text { injected } 290{ }^{\circ} \mathrm{C} ; \\
\text { aged } 300^{\circ} \mathrm{C}, 2 \mathrm{~h}\end{array}$ \\
\hline $\mathrm{PdP}_{2}$ & $26.1 \mathrm{mg} \mathrm{Pd}+2.0 \mathrm{~mL}$ TOP & $2.0 \mathrm{~g} \mathrm{TOPO}$ & $360{ }^{\circ} \mathrm{C}, 2 \mathrm{~h}$ \\
\hline $\mathrm{Pd}_{5} \mathrm{P}_{2}$ & $19.5 \mathrm{mg} \mathrm{Pd}(\mathrm{acac})_{2} *$ & $2.0 \mathrm{~mL} \mathrm{TOP}$ & $300{ }^{\circ} \mathrm{C}, 0.5 \mathrm{~h}$ \\
\hline $\mathrm{Au}_{2} \mathrm{P}_{3}$ & $3.1 \mathrm{mg} \mathrm{Au}+2.0 \mathrm{~mL}$ TOP & $2.0 \mathrm{~g} \mathrm{TOPO}$ & $360^{\circ} \mathrm{C}, 6 \mathrm{~h}$ \\
\hline $\mathrm{PtP}_{2}$ & $18.0 \mathrm{mg} \mathrm{Pt}+1.0 \mathrm{~mL}$ TOP & $2.0 \mathrm{~mL} \mathrm{TOP}$ & $370{ }^{\circ} \mathrm{C}, 2 \mathrm{~h}$ \\
\hline $\mathrm{Rh}_{2} \mathrm{P}$ & $8.7 \mathrm{mg} \mathrm{Rh}+2.0 \mathrm{~mL}$ TOP & $2.0 \mathrm{~g} \mathrm{TOPO}$ & $360^{\circ} \mathrm{C}, 1 \mathrm{~h}$ \\
\hline
\end{tabular}

* $\mathrm{Pd}_{5} \mathrm{P}_{2}$ particles could not be made phase-pure by injecting pre-made $\mathrm{Pd}$ nanoparticles dispersed in TOP into a hot solvent. Multi-phase $\mathrm{Pd}_{5} \mathrm{P}_{2} / \mathrm{PdP}_{2}$ is accessible by injecting $\mathrm{Pd}$ particles dispersed in TOP into $330{ }^{\circ} \mathrm{C}$ TOPO. Instead, phase-pure $\mathrm{Pd}_{5} \mathrm{P}_{2}$ can be made by heating $\mathrm{Pd}(\text { acac })_{2}$ in TOP to $300{ }^{\circ} \mathrm{C}$ for 0.5 hours, during which Pd particles first form at $220{ }^{\circ} \mathrm{C}$ and are converted to $\mathrm{Pd}_{5} \mathrm{P}_{2}$ by further heating. 

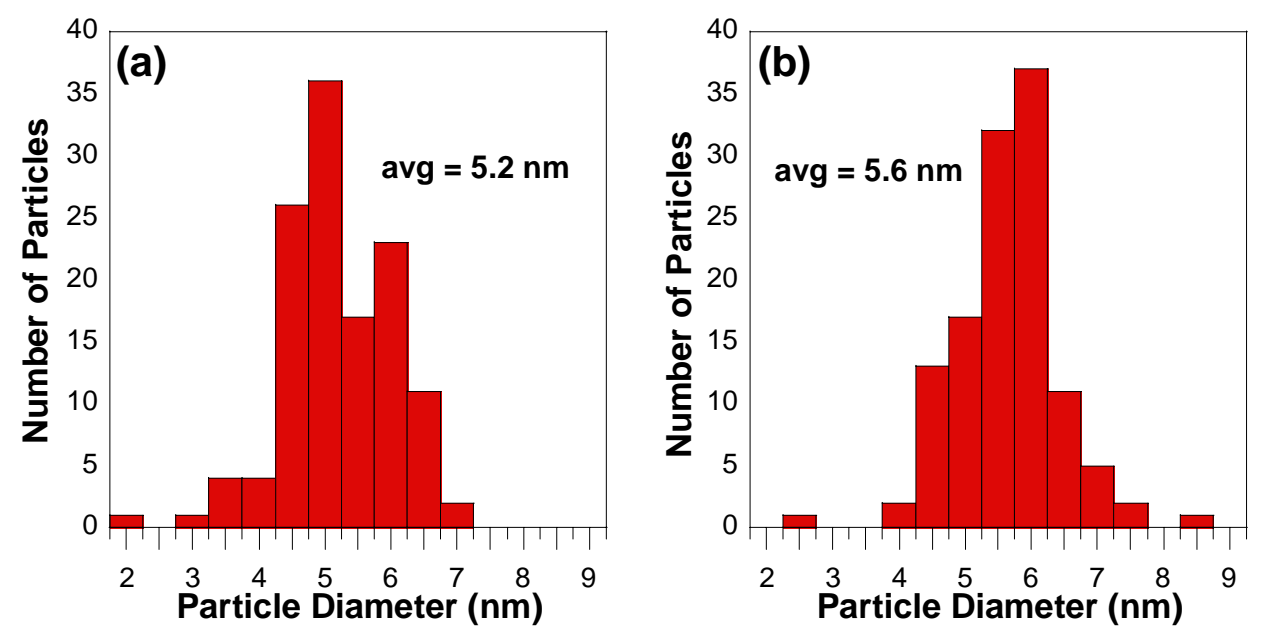

Figure S1. Histograms of particle size distribution for (a) Ni nanoparticles made using method 2 (from reference 3 ) and (b) $\mathrm{Ni}_{2} \mathrm{P}$ formed from their reaction with TOP. The predominant particle sizes are $5 \mathrm{~nm}$ for $\mathrm{Ni}$ and $6 \mathrm{~nm}$ for $\mathrm{Ni}_{2} \mathrm{P}$.
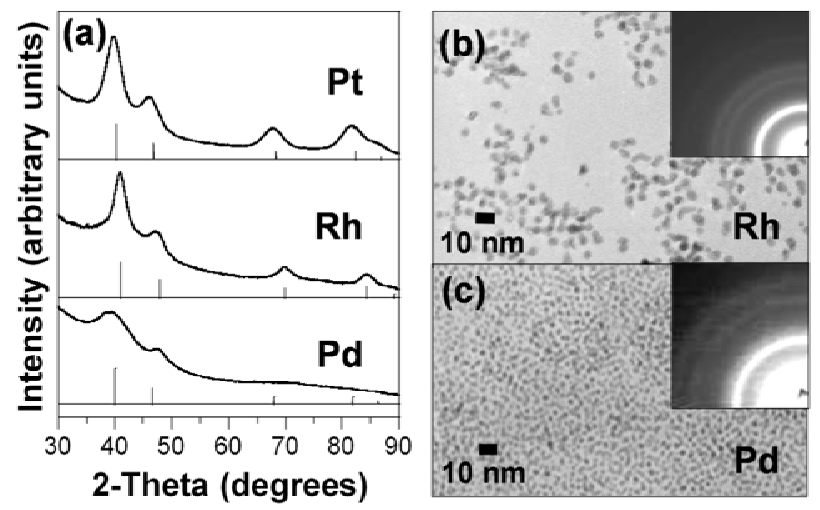

Figure S2. (a) Powder XRD patterns for Pt, Rh and Pd nanoparticle precursors; TEM and SAED images of (b) Rh and (c) Pd nanoparticles. 

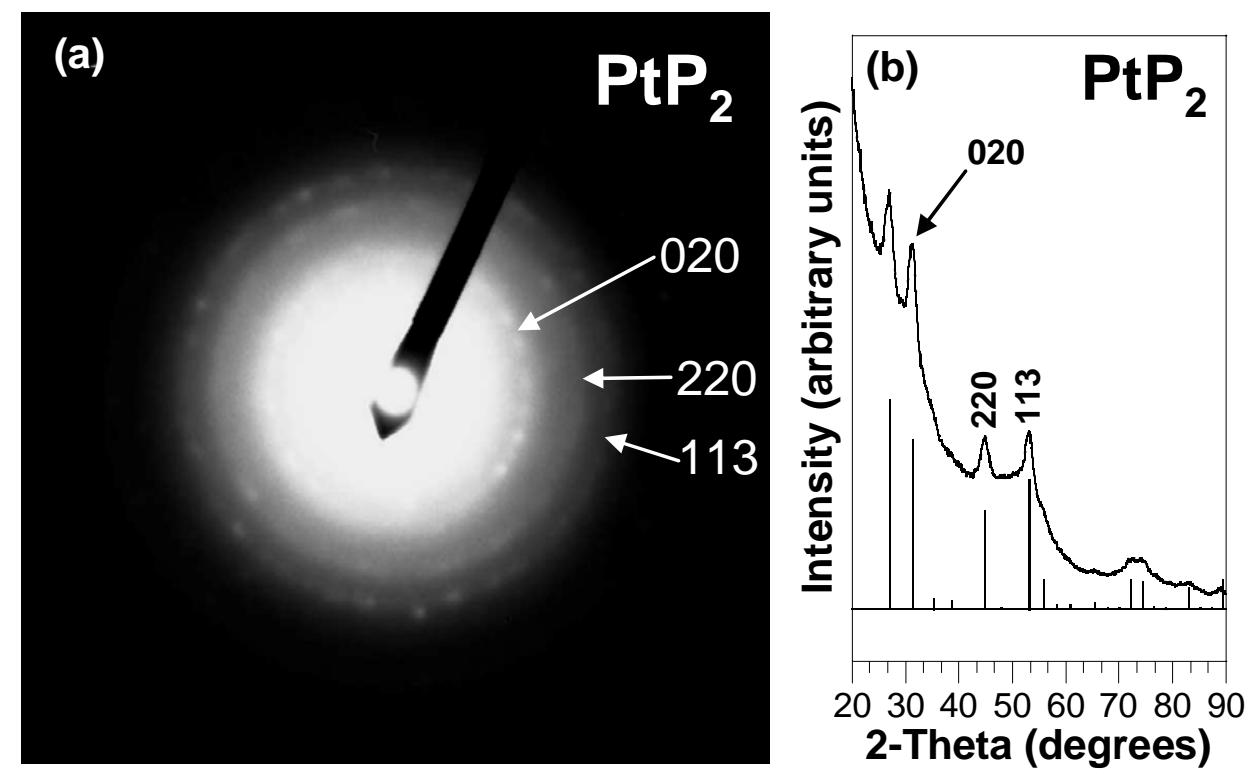

Figure S3. (a) Enlarged SAED image and (b) powder XRD for $\mathrm{PtP}_{2}$ nanocrystals, with major planes indexed.
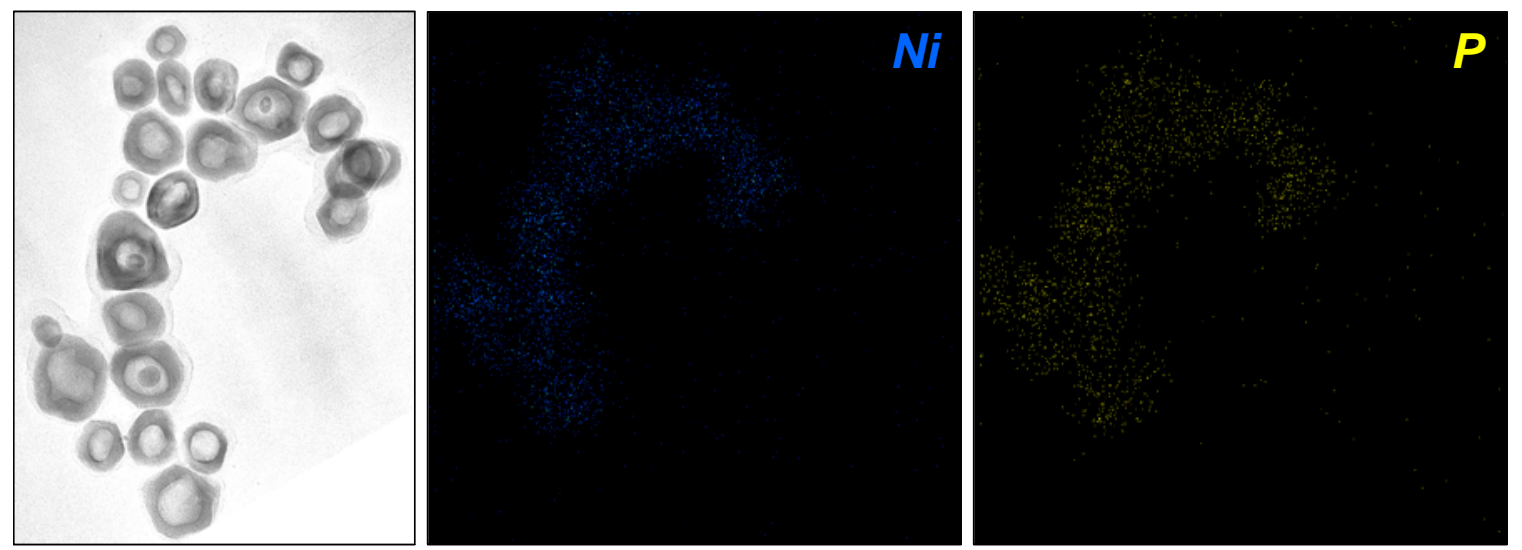

Figure S4. TEM micrograph and EDS element mapping data for $\mathrm{Ni}_{2} \mathrm{P}$ hollow nanospheres, showing the presence of both $\mathrm{Ni}$ and $\mathrm{P}$ in the nanostructures. 


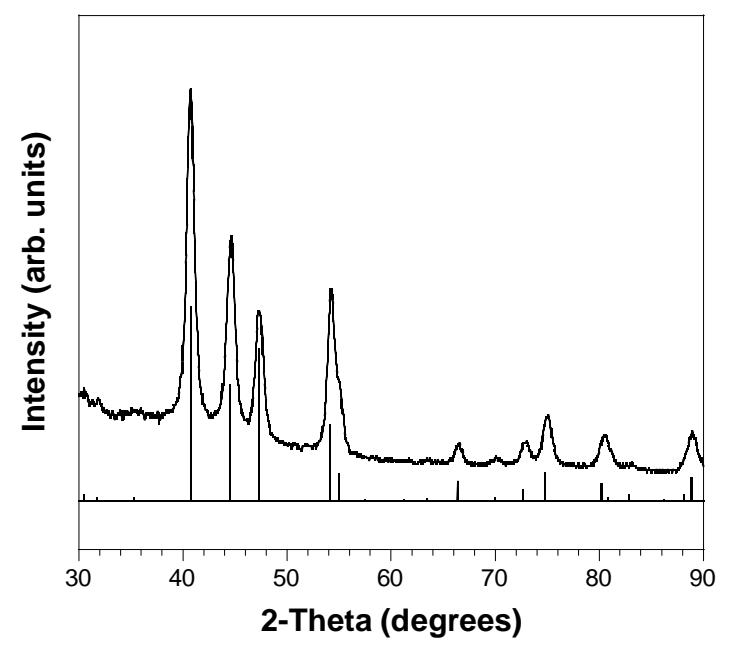

Figure S5. XRD pattern for the hollow $\mathrm{Ni}_{2} \mathrm{P}$ nanospheres shown in Figures 3 and S4.

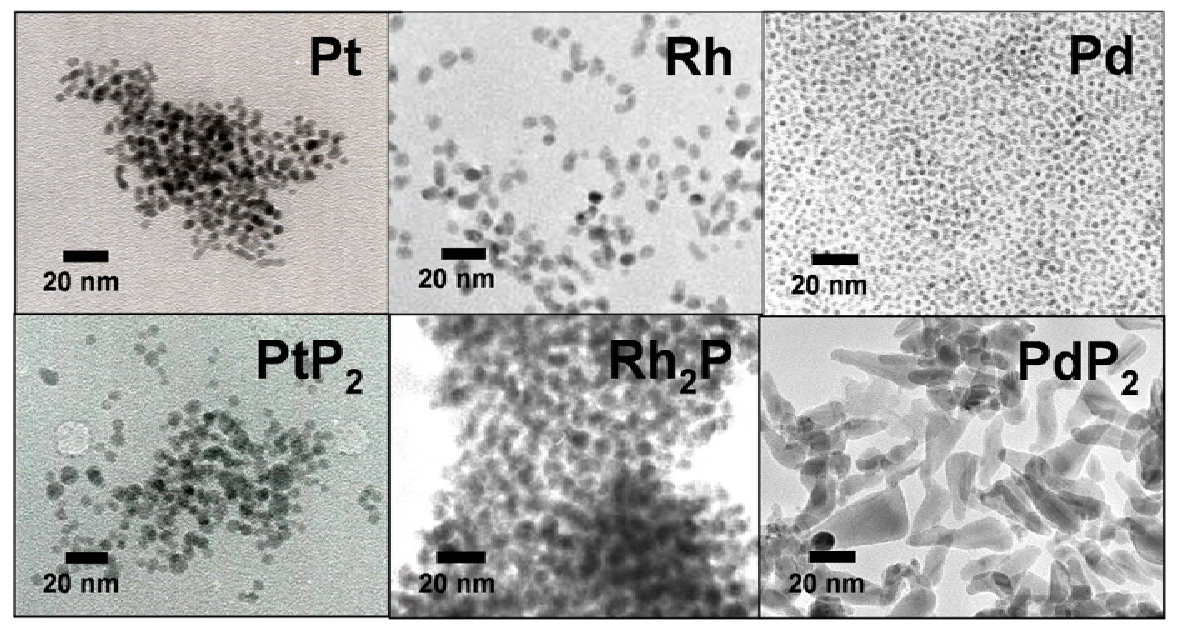

Figure S6. TEM micrographs showing metal nanoparticle precursors (Pt, Rh, $\mathrm{Pd})$ and the metal phosphide products $\left(\mathrm{PtP}_{2}, \mathrm{Rh}_{2} \mathrm{P}, \mathrm{PdP}_{2}\right)$ that are derived from them via reaction with TOP. For $\mathrm{PdP}_{2}$, the Pd nanoparticle precursors are much smaller than the $\mathrm{PdP}_{2}$ products, implying that more than one Pd nanoparticle serves as a precursor for the formation of a single $\mathrm{PdP}_{2}$ particle. This, in turn, implies a slightly different reaction pathway for the formation of $\mathrm{PdP}_{2}$ compared to the other metal phosphides, which more closely match the shape and size dispersity of the metal nanoparticle precursors.

\footnotetext{
${ }^{1}$ (a) Son, S. U.; Jang, Y.; Yoon, K. Y.; Kang, E.; Hyeon, T. Nano Lett. 2004, 4, 1147-1151. (b) Kim, S.-W.; Park, J.; Jank, Y.; Chung, Y.; Hwang, S.; Hyeon, T.; Kim, Y. W. Nano. Lett. 2003, 3, 1289-1291.

2 Grebinski, J. W.; Richter, K. L.; Zhang, J.; Kosel, T. H.; Kuno, M. J. Phys. Chem. B 2004, 108, 9745-9751.

${ }^{3}$ Park, J.; Kang, E.; Son, S. U.; Park, H. M.; Lee, M. K.; Kim, J.; Kim, K. W.; Noh, H.-J.; Park, J.-H.; Bae, C. J.; Park, J.-G.; Hyeon, T. Adv. Mater. 2005, 17, 429-434.
} 